\title{
Construção e aplicação de uma proposta de ensino de história e música popular no ensino médio integrado
}

Construction and application of a proposal for teaching history and popular music in integrated

\author{
high school
}

Construcción y aplicación de una propuesta para la enseñanza de historia y musica popular en la escuela secundaria integral

\section{Resumo}

O presente artigo procura apresentar a construção de uma proposta de ensino versada na análise da canção popular como objeto de estudo e documento histórico, elaborada com base nas discussões teórico-metodológicas levantadas por Napolitano (2007, 2016), Hermeto (2012), Tatit (2004), Naves (2010), dentre outros, dialogando sua aplicabilidade no ensino de História mediante os conceitos de Cultura Histórica (Soares, 2017; Rocha, 2014), Consciência Histórica (Rüsen, 2001) e Consciência Crítica (Freire, 2010). Ademais, considerando o contexto do ensino médio integrado, foi estabelecido uma relação direta com o constructo conceitual da Educação Profissional e Tecnológica trabalhado por autores como Gramsci, Saviani, Frigotto, Ciavatta e Ramos. Metodologicamente, a pesquisa possuiu um caráter qualitativo, de tipo Intervenção Pedagógica (Damiani, 2012; et al., 2013), como forma de aplicação e avaliação da proposta de ensino. Tal processo se deu através de um minicurso realizado com estudantes do ensino médio integrado do Instituto Federal de Educação, Ciência e Tecnologia da Paraíba - Campus Cajazeiras, todos voluntariamente inscritos. A pesquisa indicou que aliar História e Música estimula a participação estudantil, além de demonstrar como a canção popular, trabalhada como objeto de estudo e documento histórico, pode ser um importante elemento no processo de construção do horizonte da formação integral.

Palavras-chave: Educação profissional e tecnológica; Ensino médio integrado; Proposta de ensino; Ensino de história; Canção popular.

\footnotetext{
Abstract

The aim of this paper is to present a teaching proposal by the usage of the analysis of popular music as research subject and as historical source. This proposal is based on the methodological and theoretical discussions of authors as Napolitano (2007, 2016), Hermeto (2012), Tatit (2004), Naves (2010); thinking of its applicability in the teaching of History by the concepts of Historical Culture (Soares, 2017; Rocha, 2014), Historical Consciousness (Rüssen, 2001) and Critical Consciousness (Freire, 2010). Furthermore, considers the integrated High School level by the concept of the Technological and Professional Education presented by Gramsci, Saviani, Frigotto, Ciavatta and Ramos. The research used a qualitative investigation by a Pedagogical Intervention (Damiani, 2012; et al., 2013), as an instrument of application and evaluation of this teaching proposal. A mini-course was offered for Integrated High School students of the Federal Institute of Education, Science and Technology of Paraíba - Campus Cajazeiras. The research indicates that ally Music and History increases the participation of the students, besides shows how the popular music can be an important component on the full education.

Keywords: Technological and professional education; Integrated high school level; Teaching proposal; Teaching of history; Popular music.

\section{Resumen}

Esta ponencia presenta la construcción de una propuesta de enseñanza basada en el analisis de la canción popular como objecto de estudio y documentación histórica. La propuesta fué elaborada basada en las discuciones teóricometodológicas de Napolitano (2007, 2016), Hermeto (2012), Tatit (2004), Naves (2010), y demás, discutiendo su aplicabilidad en la enseñanza de História bajo los conceptos de Cultura Histórica (Soares, 2017; Rocha, 2014),
} 
Consciencia Historica (Rüsen, 2001) y Consciencia Critica (Freire, 2010). Además, considerando el contexto de la escuela secundaria integral, estableció una relacción directa con el constructo conceptual de la Educación Profesional y Tecnológica discutido por autores como Gramsci, Saviani, Frigotto, Ciavatta y Ramos. Como metodologia, la pesquisa fué calitativa, en la forma de una Intervención Pedagógica (Damiani, 2012; et al., 2013), como instrumento de aplicación e evaluación de la propuesta de enseñanza. Este proceso ocurrió con la oferta de un minicurso con los Estudiantes de la escuela secundária integral del Instituto Federal de Educación, Ciencia y Tecnologia de la Paraíba Campus Cajazeiras. La pesquisa indica que combinar Música y Historia estimula la participación de los Estudiantes, mas allá de demonstrar como la canción popular, pensada como objecto de estudio y documentación histórica, puede ser un importante instrumento en el processo de construcción del horizonte de la formación integral.

Palabras clave: Educación professional y tecnológica; Escuela secundária integral; Propuesta de enseñanza; Enseñanza de história; Canción popular.

\section{Introduçãa}

A área de estudos em música não possui delimitações fronteiriças bem definidas. Ela é utilizada por diversas áreas do conhecimento, a exemplo da Musicologia, da Linguística, da Antropologia, da Sociologia, da História etc. Além do desafio de estabelecer um grande diálogo do tema perante tal diversidade, é perceptível, no entanto, uma dicotomia no trato do objeto sob duas abordagens: uma de caráter interno à obra musical (elementos estético-musicais, literários) e outra que considera questões externas, tais como ideologia, conjuntura, tecnologia, mercado musical etc. (Napolitano, 2007).

Descendo o assunto para a música popular, caracterizada enquanto síntese entre a música "ligeira" e a música de caráter tradicionalista e comunitária (Napolitano, 2016), o assunto ganha mais camadas de discussão, pois coloca-nos em um grande sistema de valores, divisões socioculturais e políticas, envolvendo sobretudo outros recortes, como questões de classe, de identidades, de regiões, dentre outras.

É perceptível que a música enquanto fenômeno artístico-cultural desperta sensações das mais diversas. Ela ocorre no tempo e no espaço. Hermeto (2012) considera que a música é elemento relevante na constituição da cultura histórica dos sujeitos. Napolitano (2016), por sua vez, compreende que a música - principalmente a música popular, é um objeto sociocultural complexo e multifacetado.

Dessa maneira, cremos que a música popular (e, por conseguinte, a canção popular - variante considerada nos limites deste trabalho) constitui-se em importante fonte sobre o comportamento social e suas nuances, e, além disso, numa poderosa ferramenta de utilização em processos educativos, das mais diversas possibilidades didáticas e curriculares. A diversidade de áreas de conhecimento, abordagens e sensações, coloca o pesquisador e/ou professor de História na tarefa de organizar os preceitos teórico-metodológicos que ancoram sua abordagem. Seu uso, porém, não se limita a um aspecto simplesmente lúdico de reprodução ou mesmo como "ilustração" de acontecimentos passados. Neste último aspecto, Hermeto sinaliza que não se deve apenas "ilustrar fatos e/ou acontecimentos históricos, (mas) espera-se que o professor conheça e seja capaz de traduzir para seus alunos os processos de leitura e interpretação de um produto cultural” (Hermeto, 2012, p.14). Acrescentamos que a multiplicidade de camadas e sentidos colocados neste produto cultural não deve perder a perspectiva de totalidade. Alijada deste último aspecto, a canção e seus fundamentos técnico-musicais, formas de produção, o diálogo letra-música, os mecanismos e instituições de mediação entre o artista e o público, dentre outros, não raramente são deixados de lado. Isso pode inviabilizar uma problematização da canção popular na perspectiva de uma história da música, o que a inseriria numa história total (Burke, 2002).

O presente artigo nasce a partir de uma pesquisa de mestrado (Dantas, 2019b). Sua aplicação se deu no contexto do Instituto Federal de Educação, Ciência e Tecnologia da Paraíba (IFPB), Campus Cajazeiras, local de trabalho do pesquisador enquanto servidor Técnico em Assuntos Educacionais. Este possui graduação em História e especialização em História do Brasil. 
Apesar de não oferecer cursos formais na área de Música, o IFPB - Campus Cajazeiras possui um considerável número de estudantes e servidores (docentes e técnicos administrativos) que frequentemente praticam a escuta musical e/ou são instrumentistas/cancionistas amadores ou profissionais. Em muitos diálogos estabelecidos no meio, frequentemente surgem questões acerca da necessidade de melhor ater-se à música nas atividades-fim da instituição (ensino, pesquisa e extensão). Quando o assunto versa sobre o campo das Ciências Humanas, costumeiramente percebia-se relatos de estudantes sobre a utilização de música (aqui nos referindo-se à canção gravada - o fonograma), porém de forma limitada, desconsiderando aspectos relacionados sobretudo às questões harmônicas, melódicas e rítmicas. Por outro lado - e isso também faz parte da experiência pesquisador, é comum deparar-se com situações de escolhas de canções a partir da afinidade musical do professor ou, ainda, da citação da letra de uma canção no material didático (livro, apostilas etc.).

Outrossim, para verificar se haveria alguma orientação na perspectiva apresentada, averiguamos os Planos Pedagógicos dos cursos técnicos integrados ao ensino médio do IFPB - Campus Cajazeiras. São eles: Edificações (2006), Eletromecânica (2015), Informática (2013) e Meio Ambiente (2014). Dois deles, Eletromecânica (p. 61, 97 e 141) e Informática (p. 75 e 79), preveem, nos procedimentos metodológicos, o uso de "análises de obras e produções artísticas". No entanto, não há menção acerca de como isso seria realizado ou mesmo quais os referenciais a se considerar.

A pesquisa se insere na tentativa de superar tal situação, no ponto de vista dos procedimentos teórico-metodológicos de trato com a canção popular (sob forma de fonograma), bastante comum no cotidiano da comunidade escolar. Como objetivo geral, ensejamos aplicar e avaliar uma proposta de ensino de História que utilize a canção popular enquanto objeto de estudo e documento histórico, através de um minicurso com discentes do Ensino Médio Integrado do IFPB - Campus Cajazeiras. Os objetivos específicos foram: a) aplicar uma proposta de ensino de História versada na análise da canção popular como objeto de estudo e documento, através de uma oficina/minicurso com discentes do IFPB - Campus Cajazeiras; b) avaliar as atividades desenvolvidas com os estudantes participantes, baseando-se na pesquisa de tipo intervenção pedagógica; e, finalizar a proposta de ensino na forma de um produto educacional. Pensando sobre como poderia se apresentar uma situação de aplicação da proposta de ensino, optou-se pela realização de um minicurso/oficina com participação voluntária dos interessados, estudantes do ensino médio integrado do IFPB Cajazeiras.

Considerando os objetivos da pesquisa, de forma a propiciar a aplicabilidade da proposta, integramos os pressupostos teórico-metodológicos de análise da canção popular definidos a uma temática corriqueiramente abordada em diversos segmentos e espaços da sociedade brasileira: O regime militar instaurado no Brasil em 1964, especialmente o período denominado como "anos de chumbo". Com isso, a proposta de ensino teve como título: Primavera nos Dentes - História e Música nos Anos de Chumbo. O título faz menção a uma canção (Primavera nos Dentes) do conjunto Secos e Molhados, lançada em 1973.

Longe de ser a única temática possível para se trabalhar com canção popular, consideramos, contudo, que o todo o período da ditadura civil-militar (1964-1985) seja bastante evidente do quanto os processos culturais (especialmente no tocante à canção popular) possuem interferência direta na dinâmica do país, muito além de mera ilustração de fatos, mas interagindo com o meio, constituindo-se, portanto, em oportuna temática para se trabalhar com a canção popular tanto como objeto de estudo quanto documento histórico.

Da mesma foma, sendo um tema corriqueiramente abordado em diversos espaços para além da escola e, além disso, considerando uma série de revisionismos e disputas em torno do tema e do legado do Regime Militar, tais como "ditabranda" ou "mal necessário", buscou-se contribuir para a produção do conhecimento crítico, principalmente na área de História.

A proposta de ensino foi construída contendo três objetivos como base: dimensionar o contexto político, econômico, social e cultural do regime militar, enfaticamente os primeiros anos do regime e o período no qual a repressão recrudesce; historicamente contextualizar o que convencionou-se chamar de moderna música popular brasileira; analisar canções de 
gêneros musicais formatados nas décadas de 1960 e 1970, valendo-se dos referenciais teórico-metodológicos propostos. Foram definidas quatro canções para se trabalhar. São elas: Cálice (Chico Buarque), Eu Te Amo Meu Brasil (Os Incríveis), Panis et Circensis (Os Mutantes) e Pare de Tomar a Pílula (Odair José).

\section{Metodologia}

A pesquisa realizada foi do tipo Intervenção Pedagógica. Damiani et al. (2013, p. 58) afirma que a intervenção consiste em "investigações que envolvem o planejamento e a implementação de interferências (mudanças, inovações) destinadas a produzir avanços, melhorias, nos processos de aprendizagem dos sujeitos que delas participam - e a posterior avaliação dos efeitos dessas interferências”.

Trata-se, portanto, de uma pesquisa aplicada. Sobre tal, Robson (1995 citado em Damiani et al., 2013, p. 58) reflete que a pesquisa aplicada é importante para "subsidiar tomadas de decisões acerca de mudanças em práticas educacionais, promover melhorias em sistemas de ensino já existentes, ou avaliar inovações”. Percebe-se, a partir dessa premissa, que a este caráter de pesquisa infere sobremaneira na prática. No caso em tela, na prática de ensino-aprendizagem.

Damiani et al. (2013, p. 60) frisa que nesse tipo de pesquisa a responsabilidade de identificação do problema e de sua proposta de resolução é do pesquisador. Contudo, na perspectiva do aprimoramento do trabalho, ele deve estar aberto às críticas e sugestões dos demais participantes. Tais pressupostos permitem-nos constatar que a pesquisa possui o caráter qualitativo já que busca as interpretações de significados do público participante, exigindo uma permanente reflexão por parte da atuação do pesquisador.

Damiani (2012) adverte, ainda, da necessidade de evidenciar o caráter investigativo da intervenção, que ajuda a fortalecer a pesquisa enquanto tal. Nesse sentido, trataremos a seguir o desenrolar da pesquisa sob dois aspectos: o método da intervenção e o método da avaliação da intervenção.

A pesquisa ocorreu no IFPB - Campus Cajazeiras. Realizada as etapas de autorização, partiu-se para a seleção do ambiente propício à realização da pesquisa. Importante registrar a necessidade de se adequar um espaço para a prática da escuta musical, considerando que neste serão realizadas as audições de canções, além da veiculação de outras mídias audiovisuais previstas à utilização no decorrer do minicurso.

A atividade foi planejada para ocorrer em horário oposto às aulas dos estudantes. Inscrições foram abertas aos interessados. Cada interessado recebeu esclarecimentos sobre a realização da pesquisa, bem como os termos de consentimento e assentimento. $\mathrm{O}$ auxílio de um estudante do campus durante todo o processo foi fundamental para que atividade se desenvolvesse.

O minicurso consistiu na aplicação da proposta de ensino elaborada previamente, considerando os objetivos da pesquisa, a metodologia proposta, as condições objetivas do local de sua realização e o tempo necessário para o desenvolvimento das atividades programadas. $\mathrm{O}$ tema escolhido para se tratar a canção como objeto de estudo e também como documento histórico foi o regime militar, focando no período de maior agudização, estabelecido pelo Ato Institucional no 5 .

A proposta de ensino foi construída sob influência do sequencial de atividades proposto por Aguiar Jr. (2005), conforme apontado no Quadro 1: 
Quadro 1 - Fases do ensino.

\begin{tabular}{|l|l|}
\hline \multicolumn{1}{|c|}{ Fases do Ensino } & \multicolumn{1}{c|}{ Propósitos (intenções) do Professor } \\
\hline Problematização inicial & $\begin{array}{l}\bullet \text { Engajar os estudantes, intelectual e emocionalmente, com o estudo do } \\
\text { tema. } \\
\bullet \text { Explorar as visões, conhecimentos prévios e interesses dos estudantes } \\
\text { sobre o tema. }\end{array}$ \\
\hline Desenvolvimento da narrativa do ensino & $\begin{array}{l}\bullet \text { Disponibilizar as ideias e conceitos da ciência e/ou das artes no plano } \\
\text { social da sala de aula. }\end{array}$ \\
\hline Aplicação dos novos conhecimentos & $\begin{array}{l}\text { - Dar oportunidades aos estudantes de falar e pensar com as novas } \\
\text { ideias e conceitos, em pequenos grupos e por meio de atividades com } \\
\text { toda a classe. } \\
\text { - Dar suporte aos estudantes para produzirem significados individuais, } \\
\text { internalizando essas ideias. } \\
\text { - Dar suporte aos estudantes para aplicar as ideias ensinadas a uma } \\
\text { variedade de contextos e transferir aos estudantes controle e } \\
\text { responsabilidade pelo uso dessas ideias. }\end{array}$ \\
\hline Reflexão sobre o que foi apreendido & $\begin{array}{l}\bullet \text { Prover comentários e reflexões sobre o conteúdo, de modo a } \\
\text { sistematizar, generalizar e formalizar os conceitos apreendidos. } \\
\text { - Destacar relações entre os conceitos e destes com outros tópicos do } \\
\text { currículo, promovendo, assim, o desenvolvimento da narrativa do } \\
\text { ensino. }\end{array}$ \\
\hline
\end{tabular}

Fonte: Aguiar Jr. (2005, p. 25).

O Quadro 1 apresenta um sequencial de etapas para o processo proposto de construção do conhecimento, com seus respectivos propósitos. Registre-se a preocupação do autor em, dentre outros aspectos, envolver os estudantes e seu universo, algo que será discutido adiante.

A avaliação do processo de intervenção pedagógica foi realizada com base nos dados levantados durante todo o processo de aplicação do produto educacional. Para tal, foram utilizados os métodos de pesquisa listados a seguir: a) Observação direta: registros realizados pelo pesquisador durante a execução da pesquisa; b) Questionário: Roteiro com questões abertas sobre o minicurso, aplicado no último momento da intervenção pedagógica.

\section{Resultados e Discussão}

\subsection{Pressupostos teórico-metodológicos para o uso da canção popular como objeto de estudo e documento histórico}

O século XX é marcado pela consolidação da música popular como produto cultural de contundente penetração em todas as camadas e classes sociais. Segundo Napolitano (2007), a música popular é o resultado do encontro ocorrido entre a música ligeira e as músicas tradicionais, as danças de salão e as danças folclóricas, no final do século XIX. O autor sublinha que ela reúne

[...] elementos musicais, poéticos e performáticos da música erudita (o lied, a chançon, árias de ópera, bel canto, corais etc.), da música "folclórica" (danças dramáticas camponesas, narrativas orais, cantos de trabalho, jogos de linguagem e quadrinhas cognitivas e morais e do cancioneiro "interessado" do século XVIII e XIX - músicas religiosas ou revolucionárias, por exemplo). (Napolitano, 2016, p. 11-12).

O autor segue afirmando que a música popular é um fenômeno da crescente urbanização ocorrida no século XIX e do consequente florescimento de grandes contingentes populacionais nas grandes cidades com a expansão das classes pobres e médias. A música nos termos aqui definidos, portanto, tem sua lógica de fundação no contexto da expansão do capitalismo monopolista da sociedade burguesa industrial do século XIX, que favoreceu a procura por este tipo de música oriunda da vida e do lazer urbanos, e o surgimento de um denso mercado musical, fundamental para a consolidação de um produto da música popular: o fonograma. Trata-se da canção popular gravada. Por lógica de fundação compreende-se as três formas básicas de 
experiência musical moderna que, ainda segundo o autor, formaram a linguagem do que se convencionou como música popular: a audiência/execução isolada, o espetáculo dramático e as reuniões de dança. (Napolitano, 2016).

Com a mesma perspectiva, Hermeto (2012, p. 32) define canção como

uma narrativa que se desenvolve num interregno temporal relativamente curto (em média, dois a quatro minutos), que constrói e veicula representações sociais, a partir da combinação entre melodia e texto (em termos mais técnicos, melodia, harmonia, ritmo e texto). Produzida em tempos de indústria fonográfica - no seio dela ou em relação com ela, ainda que marginal -, circula majoritariamente por meio de registros sonoros, sendo veiculada através dos meios de comunicação de massa (rádio, TV e mídias digitais, por exemplo).

A música sob forma de canção se concebe enquanto produto formatado no século XX. Já a área do conhecimento História notou a música popular - e suas variantes - como possibilidade concreta de estudos nos anos de 1980. Sob influência de outras áreas (Antropologia, Sociologia, Semiótica, Musicologia...), diferentes abordagens acostumaram-se a separar seus elementos no processo de análise: letra e música, autor e sociedade, produto e contexto. Já no campo da História, sob perspectiva tradicionalista, criou-se uma espécie de "linha evolutiva", que estabelece hierarquias originadas em subjetividades (ou "gosto pessoal"), o que costuma revelar preconceitos diversos. (Napolitano, 2016).

Segundo Naves (2010), a canção popular ganha hegemonia na música brasileira no século XX. Tatit (2004) enfatiza tratar-se de uma das mais firmes tradições cancionais do mundo. Ela, no entanto, apresenta elementos que carecem de problematização. Napolitano (2016, p. 77) afirma ser necessário analisar como esses elementos “articulam na canção - musical e poeticamente - as tradições, identidades e ideologias que a definem, para além das implicações estéticas mais abstratas, como um objeto sociocultural complexo e multifacetado".

Poe outro lado, Bloch (1997) afirma que o objeto da História é o conjunto formado pela interação entre os homens e o tempo, de modo a determinar quem é o sujeito da ação, de como ela se realizou no mundo e sobre como essa ação se desenvolve no tempo, considerando mudanças e permanências, bem como do tempo no qual essa ação é lembrada e (re)interpretada. Desta forma, o conhecimento histórico também é produzido em temporalidades. Ademais, precisa ser referendado por uma comunidade para ser aceito. Logo, o conhecimento é produto de um lugar social. Por sua vez, para ser científico, precisa de um cabedal de procedimentos específicos de análise, aliando conceitos, fontes e critérios (Hermeto, 2012).

Recorremos neste trabalho ao conceito de documento-monumento, no sentido formulado por Le Goff (2013), ou seja, como uma montagem que precisa ser desmontada, demolida e desestruturada para viabilizar a análise de suas condições de produção e desmistificação. A canção deve, neste caso, ser tratada como um documento-monumento. $\mathrm{O}$ autor afirma, ainda, que "só a análise do documento enquanto monumento permite à memória coletiva recuperá-lo e ao historiador usá-lo cientificamente, isto é, com pleno conhecimento de causa" (Le Goff, 2013, p. 495). Para tal, salientamos uma postura crítica e problematizadora, mas não apenas. A abordagem precisa ser histórica:

As perguntas que devem ser lançadas à fonte histórica devem informar sobre esses elementos e as relações entre eles: os sujeitos e seu contexto, seu lugar social, as distintas relações por ele vivenciadas, o ambiente em que estavam inseridos, suas identidades etc. (Hermeto, 2012, p. 26).

Supomos que para que isso ocorra no tocante à canção popular, é preciso construir problemas históricos que a coloquem em centralidade, relacionando-a às temáticas mais abrangentes, examinando-a como fonte, ou seja, interrogá-la em seus aspectos amplos e no problema que está sendo investigado. Para tanto, é preciso compreendê-la em sua linguagem específica. 
Napolitano (2016) propõe analisá-la em observância às características intrínsecas de uma canção e seus parâmetros poéticos (letra) e musicais (melodia, harmonia e ritmo). Saliente-se que a canção ocorre na interação entre esses dois parâmetros e que tal separação deve acontecer apenas para fins didáticos.

No tocante à letra, é necessário identificar o tema geral da canção - ou mote, a identificação do "eu poético" e seus interlocutores, o desenvolvimento - imagens poéticas, o léxico e a sintaxe predominantes, a(s) forma(s) poética(s) - rimas, crônicas etc., figuras e gêneros literários, além da ocorrência - ou não - de intertextualidade. Já para a música em si, sugere-se a verificação da melodia (pontos de tensão/repouso melódico, do "clima" predominante - se alegre, triste, lírico, épico...), do arranjo - instrumentos, timbres, acompanhamento, andamento, vocalização, gênero musical (ou o diálogo de gêneros diversos), ocorrência - ou não - de intertextualidade musical e efeitos eletroacústicos, bem como dos tratamentos de estúdio. (Napolitano, 2016).

Moraes (2000, p. 210) traz alguns esclarecimentos sobre o trabalho com questões específicas da música, relacionandose a atuação do historiador/professor de história:

[...] mesmo não sendo músico ou musicólogo com formação apropriada e específica, o historiador pode compreender aspectos gerais da linguagem musical e criar seus próprios critérios, balizas e limites na manipulação da documentação (como ocorrem, por exemplo, com a linguagem cinematográfica, iconográfica e até no tratamento da documentação mais comum).

Napolitano (2016, p. 99) também sugere a análise externa da canção, propondo observar as "instâncias de análise contextual". Estabelecendo uma ponte com tais instâncias, observa-se um circuito de comunicações (Hermeto, 2012), apresentando e refletindo sobre as etapas que vão da criação à recepção e apropriação pelo público. Nesse interstício existem os mecanismos de produção e circulação. A autora propõe verificar os seguintes sujeitos e processos: a) $o(s)$ cancionista(s), que promovem que promovem o encontro entre o texto e a melodia/harmonia/ritmo; b) os performers - arranjadores, instrumentistas e cantores; c) a indústria fonográfica - o produto cultural, no contexto da sociedade capitalista, também é um produto de mercado $^{1}$; d) mediadores culturais - produtores musicais, jornalistas especializados, dentre outros ${ }^{2}$; e) meios de comunicação de massa e público. Sobre este último ponto, Hermeto $(2012$, p. 86) discorre que "é na relação entre essas duas instâncias que tem início o processo de apropriação da canção popular". A autora informa que as mídias de massa são um elemento importante no circuito, fruto do desenvolvimento tecnológico que media e interfere na relação entre canção e público. Ela aponta, ainda, que a linguagem veiculada pela canção (do rádio, da TV, da internet...) influi decisivamente na apropriação do público.

\subsection{A canção popular no ensino médio integrado}

Soares (2017) sustenta que a música pode ser um oportuno recurso didático, todavia pondera que isso não garante a a produção de conhecimento por si. O professor precisa considerar o envolvimento dos discentes nas atividades propostas, ou seja, analise o processo de tomada de consciência dos alunos. Tal ideia relaciona-se com Leontiev (1978) quanto este sugere que professores e estudantes precisam ter ciência dos motivos do estudo dos temas e conteúdos apresentados.

O mesmo autor propõe a interação entre os estudos propostos e a cultura histórica dos educandos, estabelecendo um constante diálogo entre aquilo que é trazido pelos educandos e o conteúdo apresentado pelo professor. A cultura histórica

\footnotetext{
${ }^{1}$ Existem muitos estudos - alguns conflitivos - sobre a indústria cultural, em grande parte sobre o papel que ela exerce na sociedade e os mecanismos de dominação e resistência, sintonizando-se com o padrão tecnológico da época. Os estudos ainda procuram explicitar formas e formatos de padronização exercidos por ela. (Napolitano, 2016).

${ }^{2}$ Hermeto (2012, p. 79) afirma que o produtor musical é o "sujeito que estabelece o elo entre a canção e a indústria fonográfica, em geral desconhecido do grande público". Ele coordena o processo de gravação (com influência no resultado do trabalho), a concepção do disco e o investimento a ser realizado. Os jornalistas especializados ou aqueles que se debruçam sobre o tema (blogueiros, youtubers etc.), além de divulgarem a obra pronta, também fazem a crítica e são formadores de opinião.
} 
envolve "esferas de produção e usos do passado que mobilizam história e memória" (Rocha, 2014, p. 49). Nesse processo, os estudantes são capazes de produzir novos conhecimentos históricos.

Da mesma forma, essa produção pode permitir o cultivo da consciência histórica pelos estudantes. Isso ocorre com a possibilidade de estabelecimento de maneiras entendimento mais complexo a partir da reflexão sobre a própria realidade. De acordo com Rüsen

A consciência histórica não é algo que os homens podem ter ou não - ela é algo universalmente humano, dada necessariamente junto com a intencionalidade da vida prática dos homens. A consciência histórica enraíza-se, pois, na historicidade intrínseca à própria vida humana prática. Essa historicidade consiste no fato de que os homens, no diálogo com a natureza, com os demais homens e consigo mesmos, acerca do que sejam eles próprios e seu mundo, têm metas que vão além do que é o caso. (Rüsen, 2001, p. 78).

Conclui-se, dessa maneira, que o pensamento histórico é carregado pelos sujeitos naturalmente. O citado autor ainda afirma que o pensamento histórico é "[...] a soma das operações mentais com as quais os homens interpretam sua experiência da evolução temporal de seu mundo e de si mesmos, de forma tal que possam orientar, intencionalmente, sua vida" (Rüsen, 2001, p. 57).

O processo ensino-aprendizagem deve, ainda, conforme aponta Freire, estar comprometido com a transição da consciência ingênua para a consciência crítica:

Não há para mim, na diferença e na "distância" entre a ingenuidade e a criticidade, entre o saber de pura experiência feito e o que resulta dos procedimentos metodicamente rigorosos, uma ruptura, mas uma superação. A superação e não a ruptura se dá na medida em que a curiosidade ingênua, sem deixar de ser curiosidade, se criticiza. Ao criticizarse, tornando-se então, permito-me repetir, curiosidade epistemológica, metodicamente "rigorizando-se" na sua aproximação ao objeto, conota seus achados de maior exatidão (Freire, 2010, p. 31-32).

Outrossim, considerando o aparato teórico discutido até aqui, salientamos que a canção popular, com suas potencialidades e possibilidades, interage com a perspectiva de uma formação de caráter integrador, que segundo Ramos (2008, p. 4), "incorpora valores ético-políticos e conteúdos históricos e científicos que caracterizam a práxis humana”. É necessário estabelecer relação entre a educação e a prática social, bem como caracterizar o trabalho como princípio educativo (Frigotto, Ciavatta \& Ramos, 2005). A cultura em sentido amplo e - no caso em tela - o estudo da canção popular nos parâmetros teórico-metodológicos aqui dimensionados, pode possibilitar a compreensão dos fundamentos sociais e culturais que ocorrem no bojo das relações da produção moderna (Saviani, 2007).

No tocante à formação, segundo Ciavatta:

A formação integrada sugere tornar íntegro, inteiro, o ser humano dividido pela divisão social do trabalho entre a ação de executar e a ação de pensar, dirigir ou planejar. Trata-se de superar a redução da preparação para o trabalho ao seu aspecto operacional, simplificado, escoimado dos conhecimentos que estão na sua gênese científico-tecnológica e na sua apropriação histórico-social. Como formação humana, o que se busca é garantir ao adolescente, ao jovem e ao adulto trabalhador o direito a uma formação completa para a leitura do mundo e para a atuação como cidadão pertencente a um país, integrado dignamente à sua sociedade política. Formação que, neste sentido, supõe a compreensão das relações sociais subjacentes a todos os fenômenos. (Ciavatta, 2005, p. 85).

As relações sociais travadas em toda a cadeia de produção, mediação e recepção da canção popular revelam, a nosso juízo, formas de luta de classes. A dominação, por sua vez, é exercida através do acesso aos meios de produção dos bens científicos e tecnológicos que são base da produção moderna (Saviani, 2007), que ao mesmo tempo produzem e reproduzem desigualdades. 
A crítica histórica sobre a canção popular pode embasar a compreensão das relações sociais, seja em aspectos amplos ou em características específicas do objeto abordado, evidenciando relações de poder e desnudando realidades muitas vezes não abordadas pela própria historiografia convencional. É fundamental que a reflexão histórica seja pela

[...] historicidade múltipla; a problematização dos valores de apreciação e das hierarquias culturais herdadas pela memória e pela tradição; a análise dos mecanismos sociológicos, a cultura política e musical de um período e sua influência no meio musical; o ambiente intelectual, as instituições de ensino e a difusão musical (Napolitano, 2016, p. 91-92).

Essa potencialidade consiste em possibilidade de rompimento com a lógica educacional capitalista, que nega às classes sociais menos favorecidas uma formação multilateral, relegando-a o aprimoramento de competências para funções específicas demandadas pelo mercado. De outra forma, busca-se estabelecer os fundamentos para a construção de um horizonte para a formação integrada e politécnica, com a união entre trabalho e educação. É relevante salientar que o termo "trabalho" não é aqui considerado nos limites da compreensão mercadológica, mas como produção da existência humana e da própria história humana. Saviani (2007, p. 144) argumenta sobre a questão do trabalho:

Ora, o ato de agir sobre a natureza transformando-a em função das necessidades humanas é o que conhecemos com o nome de trabalho. Podemos, pois, dizer que a essência do homem é o trabalho. A essência humana não é, então, dada ao homem; não é uma dádiva divina ou natural; não é algo que precede a existência do homem. Ao contrário, a essência humana é produzida pelos próprios homens. O que o homem é, é-o pelo trabalho. A essência do homem é um feito humano. É um trabalho que se desenvolve, se aprofunda e se complexifica ao longo do tempo: é um processo histórico.

Da mesma forma, o autor aponta para uma perspectiva ontológica da educação:

Se a existência humana não é garantida pela natureza, não é uma dádiva natural, mas tem de ser produzida pelos próprios homens, sendo, pois, um produto do trabalho, isso significa que o homem não nasce homem. Ele forma-se homem. Ele não nasce sabendo produzir-se como homem. Ele necessita aprender a ser homem, precisa aprender a produzir sua própria existência. Portanto, a produção do homem é, ao mesmo tempo, a formação do homem, isto é, um processo educativo. A origem da educação coincide, então, com a origem do homem mesmo (Saviani, 2007, p. 144).

Trata-se, portanto, de propor uma educação focada no aspecto humano, numa perspectiva libertadora, que realize o necessário combate à dualidade produtora e reprodutora da sociedade de classes. Contra tal dualidade, ganha o conceito de politecnia: "Politecnia diz respeito ao domínio dos fundamentos científicos das diferentes técnicas que caracterizam o processo de trabalho produtivo moderno" (Saviani, 2003, p. 140).

Marx e Engels (2008), ainda no século XIX, aliaram educação e produção material. Por sua vez, Gramsci, já no século $\mathrm{XX}$, elabora e sistematiza um horizonte para uma escola de caráter unitário:

A escola unitária ou de formação humanista (entendido este termo, 'humanismo', em sentido amplo e não apenas em sentido tradicional) ou de cultura geral deveria se propor a tarefa de inserir os jovens na atividade social, depois de têlos levado a um certo grau de maturidade e capacidade, à criação intelectual e prática e a uma certa autonomia na orientação e na iniciativa (Gramsci, 1982, p. 121).

Estabelecendo um paralelo entre a educação unitária e o atual sistema educacional básico brasileiro, sobretudo no que concerne à última etapa proposta por Gramsci (que, no caso brasileiro, equivaleria ao ensino médio): 
[...] a última fase deve ser concebida e organizada como a fase decisiva, na qual se tende a criar os valores fundamentais do 'humanismo', a autodisciplina intelectual e a autonomia moral necessárias a uma posterior especialização, seja ela de caráter científico (estudos universitários), seja de caráter imediatamente prático-produtivo (indústria, burocracia, comércio etc.). O estudo e o aprendizado dos métodos criativos na ciência e na vida devem começar nesta última fase da escola, não devendo mais ser um monopólio da universidade ou ser deixado ao acaso da vida prática: esta fase escolar já deve contribuir para desenvolver o elemento da responsabilidade autônoma dos indivíduos, deve ser uma escola criadora (Gramsci, 2001, p. 39).

Os fundamentos acima apresentados formam base para uma educação pública, gratuita e de qualidade no país, tendo como base a formação integral, em perspectiva omnilateral. Para Frigotto, educação omnilateral significa

a concepção de educação ou formação humana que busca levar em conta todas as dimensões que constituem a especificidade do ser humano e as condições objetivas e subjetivas reais para o seu pleno desenvolvimento histórico. Essas dimensões envolvem sua vida corpórea material e seu desenvolvimento intelectual, cultural, educacional, psicossocial, afetivo, estético e lúdico. Em síntese, educação omnilateral abrange a educação e a emancipação de todos os sentidos humanos, pois os mesmos não são simplesmente dados pela natureza (Frigotto, 2012, p. 265).

Dessa forma, advogamos que o exercício de tornar a canção popular, ao mesmo tempo, objeto de estudo e documento histórico resulta na colaboração para o constructo da formação integrada tendo em vista que revela e dimensiona na canção o trabalho, a ciência e a cultura como realizações humanas, historicamente assentadas no contraditório avanço produtivo e tecnológico da produção. Isso pode possibilitar um elemento de criticidade fundamental, sobretudo neste momento no qual o ensino médio se torna alvo direto de intervenções no sentido de aprofundamento de uma educação unilateral e específica para determinadas funções da sociedade capitalista, tal qual orientado no chamado "novo ensino médio" e seus itinerários formativos (Brasil, 2017), por mais que estejam vigentes o princípio da centralidade do trabalho, integrando-se à ciência, à cultura e à tecnologia (Brasil, 2021). Aliás, essa contradição na legislação educacional brasileira, tanto atual quanto historicamente, é apontada por Ramos (2021) na medida em que a autora cita diversos embates com vias à educação emancipatória e transformadora, a exemplo do movimento dos Pioneiros da Educação ou do método Paulo Freire de Educação Popular, ou ainda dos debates no contexto da elaboração da Lei de Diretrizes e Bases da Educação Nacional (Brasil, 1996) e de seus posteriores decretos regulamentadores acerca da relação entre Educação Profissional e Tecnológica e o Ensino Médio, mormente os decretos no 2.208 (Brasil, 1997) e nº 5.154 (Brasil, 2004).

Esse cenário de contradição, por mais que ainda exista a previsibilidade legal de se trabalhar na perspectiva de uma formação integral, é um grande desafio a ser superado, razão pela qual utilizamos neste trabalho a expressão "constructo da formação integrada".

\subsection{A proposta de ensino}

A Proposta intitulada "Primavera nos Dentes - História e Música nos Anos de Chumbo", conforme mencionado, foi elaborada, aplicada e avaliada com estudantes de cursos técnicos integrados ao ensino médio do IFPB - Campus Cajazeiras, voluntariamente inscritos em um minicurso realizado no mês de dezembro de 2019, de 5 horas de duração. A carga horária foi pensada para aplicação de forma concentrada, sem prejuízo, porém, de aplicação em realidades diversas. Sua íntegra está publicada na Plataforma EDUCAPES (Dantas, 2019a). A Figura 1 apresenta a capa da proposta: 
Figura 1 - Capa da proposta de ensino.

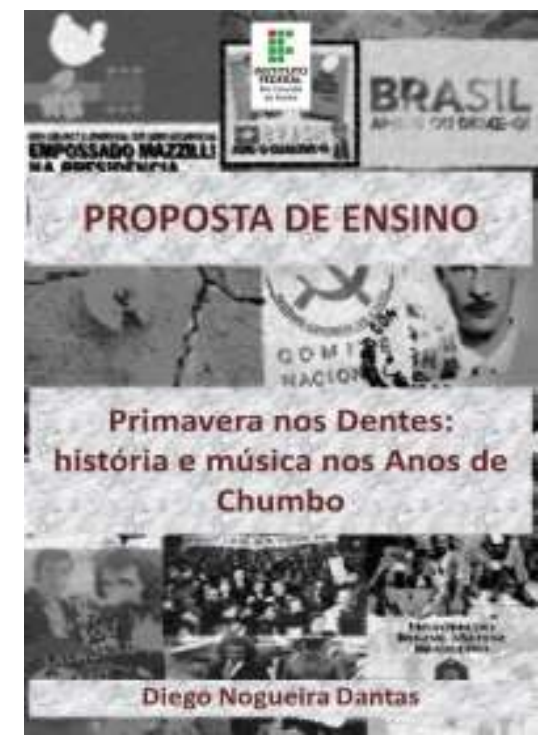

Fonte: Elaboração própria (2019).

A capa apresentada na Figura 1 foi elaborada pelos autores do presente trabalho, a partir de uma montagem com imagens contextualizadas ao tema da proposta, disponibilizadas na rede mundial da computadores.

Três objetivos balizaram sua elaboração. O primeiro foi o de dimensionar o contexto político, econômico, social e cultural do regime militar, enfatizando os anos iniciais do período (1964 em diante) e o recrudescimento da repressão a partir da promulgação do Ato Institucional no 5, em 1968. A bibliografia baseia-se em Fico (2015), Napolitano (2017), além de material referenciado consultado na internet, registrando a importância de utilizar-se literatura recente e suas novas fontes levantadas. O segundo objetivo foi fazer uma trajetória histórica da música popular brasileira contemporânea. Foram propostos os seguintes referenciais: Napolitano (2016), Hermeto (2012) e Araújo (2002). Como terceiro intento, buscamos analisar canções de gêneros consolidados nas décadas de 1960 e 1970. Inicialmente, quatro canções foram inseridas na proposta.

Cálice é uma emblemática canção do período. Foi composta por Chico Buarque e Gilberto Gil em 1973, ambos bastante reconhecidos por uma vasta produção musical, indelevelmente ligados às oposições ao regime instaurado em 1964. Foi censurada e lançada apenas em 1978. A canção foi gravada com as vozes de Chico Buarque e Milton Nascimento, outro artista de destaque.

Eu Te Amo Meu Brasil, gravada em 1970 pelo conjunto Os Incríveis, possui uma característica ufanista, valorizando aspectos da natureza e da sociedade brasileiras. Outra característica da canção é que ela não foi composta pelo grupo que a gravou, mas pelo compositor e cancionista Dom (conhecido pela dupla Dom \& Ravel). Demonstra um caminho longo a ser percorrido pela canção: a produção da obra, em estúdio, não necessariamente pertencente ao cancionista ou compositor. A canção evidencia, ainda, questões rítmicas e melódicas do universo militar.

Panis et Circensis é uma canção gravada em 1968 pela banda Os Mutantes. Trata-se de outra canção de composição diferente dos artistas que a gravaram (Caetano Veloso e Gilberto Gil). Possui elementos do movimento tropicalista, pertencente àquela quadra histórica.

Por fim, Uma Vida Só (Pare de Tomar a Pílula), é de Odair José. Gravada em 1973, trata-se de uma canção popular romântica, que no Brasil é bastante conhecida pelo termo "brega". O citado artista é um dos principais do gênero que é muito presente nas classes populares do chamado "Brasil profundo". Curiosamente era chamado de "Bob Dylan da Central do Brasil" e "Terror das Empregadas". Sofreu censura do regime, inclusive do ponto de vista moral.

O Quadro 2 apresenta o esquema da proposta de ensino: 
Quadro 2 - Panorama das atividades desenvolvidas.

\begin{tabular}{|c|c|c|c|}
\hline Problematização & $\begin{array}{c}\text { Desenvolvimento da } \\
\text { narrativa }\end{array}$ & $\begin{array}{l}\text { Aplicação dos } \\
\text { Conhecimentos }\end{array}$ & Reflexão/Síntese \\
\hline $\begin{array}{l}\text { Atividade 1: } \\
\text { Levantamento das } \\
\text { representações sociais do } \\
\text { regime militar, a partir dos } \\
\text { estudantes. }\end{array}$ & $\begin{array}{l}\text { Atividade 2: } \\
\text { Exposição dialogada sobre } \\
\text { o regime militar (contexto } \\
\text { político, econômico, social } \\
\text { e cultural), com ênfase nos } \\
\text { anos iniciais e no } \\
\text { recrudescimento do regime } \\
\text { (Anos de Chumbo). } \\
\text { Atividade 3: } \\
\text { Breve histórico da música } \\
\text { popular brasileira, com } \\
\text { enfoque nos anos } 60 \text { e } 70 .\end{array}$ & $\begin{array}{l}\text { Atividade 4: } \\
\text { Audiência orientada das } \\
\text { canções: Cálice, Eu te amo } \\
\text { meu brasil, Uma vida só } \\
\text { (Pare de tomar a pílula) e } \\
\text { Panis et circensis. }\end{array}$ & $\begin{array}{l}\text { Atividade 6: } \\
\text { Socialização dos trabalhos } \\
\text { e debate final. }\end{array}$ \\
\hline
\end{tabular}

Fonte: Elaboração própria (2021).

Conforme mencionado na sessão 2.1, a proposta de ensino se referencia no sequencial de atividades proposto por Aguiar Jr. (2005). Percebe-se que o panorama apresentado no Quadro 2 contempla as quatro fases de ensino propostas pelo autor (Problematização, Desenvolvimento da narrativa, Aplicação dos conhecimentos e Reflexão/Síntese).

Sistematizados os registros oriundos das observações durante o momento da intervenção pedagógica e as questões concernentes ao questionário aplicado, passou-se ao processo de elaboração do relatório. Damiani et al. (2013, p. 59) salienta que é pertinente descrever com detalhes todos os procedimentos realizados, avaliando-os e produzindo explicações plausíveis, fundamentadas nos dados colhidos e no embasamento teórico. Além disso, como pesquisa qualitativa, são fundamentais os cruzamentos entre os dados coletados, através de diferentes instrumentos, bem como a reflexividade e a validação comunicativa (Bauer \& Gaskell, 2002).

Os registros considerados salutares ao relatório estão contidos na dissertação (Dantas, 2019b). No entanto, cabe ressaltar aqui alguns apontamentos sobre o percurso das atividades. Em primeiro lugar, observamos o quão pertinente é o levantamento do conhecimento prévio dos alunos sobre o tema proposto. Obtivemos um rico retorno sobre as representações sociais do regime militar, revelando a cultura histórica (Soares, 2017; Rocha, 2014) edificada por eles a partir, por exemplo, de memórias de parentes que vivenciaram o período e de conhecimentos que eles produziram a partir dos estudos de disciplinas como História, Sociologia, Geografia etc. Além disso, no tocante à música, há o conhecimento sobre obras e artistas do período nas quais eles tiveram contato prévio. Ademais, alguns estudantes enfatizaram que o tema está em voga no cotidiano.

$\mathrm{Na}$ exposição dialogada (atividades 2 e 3), recebemos um retorno significativo sobre o conteúdo proposto, inclusive sobre o uso de tecnologias digitais. Na ocasião, reproduzimos e debatemos um vídeo produzido no canal do YouTube intitulado Nerdologia. Alguns alunos conheciam e se referenciavam pelo canal, que é elaborado, dirigido e apresentado por um professor de História.

As atividades 4 e 5 concentraram-se na aplicação dos conhecimentos, considerando os parâmetros que, de início, apresentamos sobre a análise da canção popular, conforme os elementos dispostos na Figura 2: 
Figura 2 - Elementos para análise de uma canção popular.

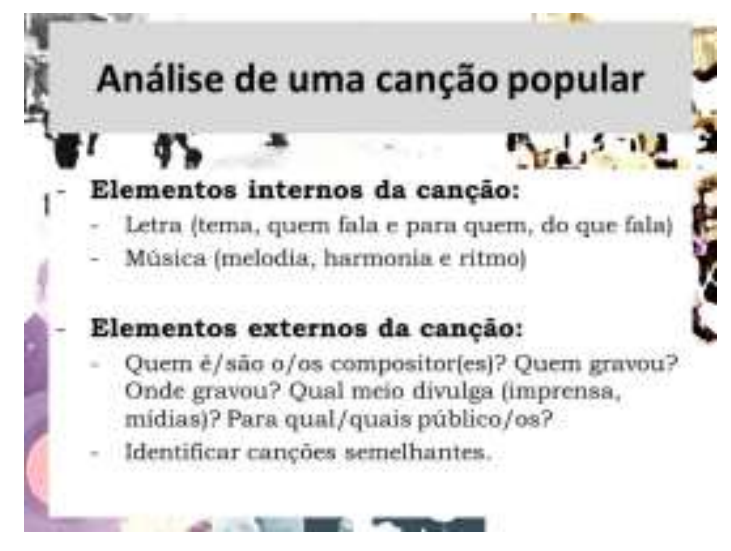

Fonte: Elaboração própria (2019).

O esclarecimento de tais elementos são relevantes para orientar a atividade seguinte.

Em seguida, realizamos audições coletivas das quatro canções propostas, fazendo observações sobre aspectos rítmicos, melódicos e harmônicos, além de textuais. Dividimos a turma em dois grupos, cada um com duas canções para se trabalhar, permitindo e incentivando a utilização de pesquisas na internet e novas audições. Também expusemos as capas dos discos que abrigam as canções, bem como distribuímos as letras e um texto informativo sobre o artista e a obra. Tudo isso serviu de base para o preenchimento de uma ficha de análise da canção popular previamente elaborada pelo ministrante do minicurso, que forneceria os subsídios para a comunicação dos trabalhos realizados e, por fim, o debate em momento posterior. A ficha segue reproduzida na Figura 3:

Figura 3 - Ficha de Análise da Canção Popular.

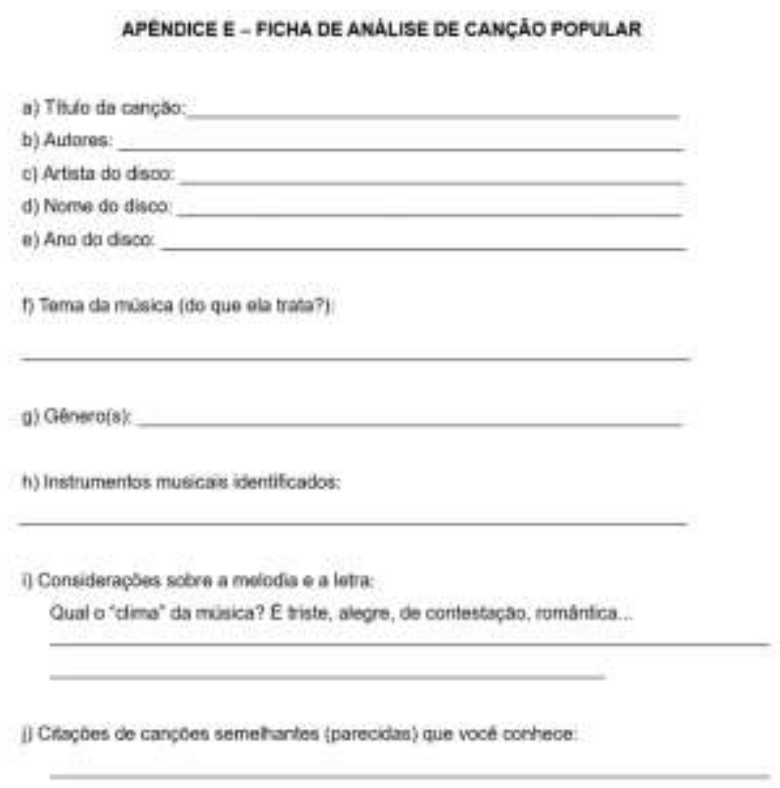

Fonte: Elaboração própria (2019).

Percebe-se que as orientações dispostas na Figura 3 estão presentes na Figura 4, trazendo, ademais, outros elementos que serão importantes para o processo de construção do conhecimento, tais como a cultura história dos educandos, bem como o 
exercício da percepção musical na tentativa de correlação entre a canção trabalhada e outras que os discentes julguem semelhantes.

Conforme mencionado, finalizamos o momento com a apresentação e o debate. Destacamos, aqui, uma intervenção sobre a satisfação dos estudantes em levantar canções semelhantes, bem como perceberem a possibilidade de aplicar essa atividade a outras temáticas e períodos da história.

Por fim, aplicamos o questionário de pesquisa para a avaliação individual do minicurso, conforme a Figura 4:

Figura 4 - Questionário de Pesquisa.

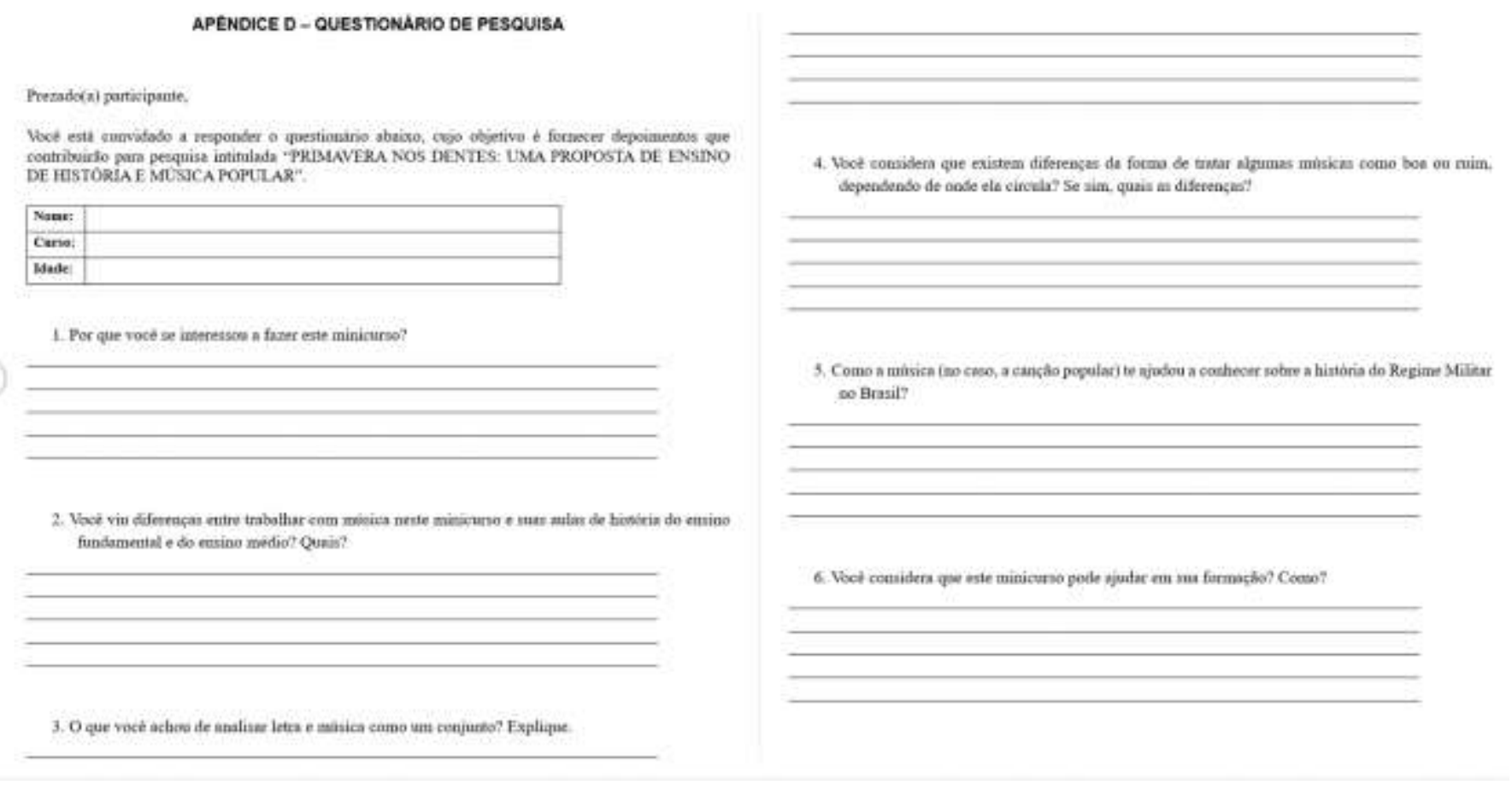

Fonte: Elaboração própria (2019).

Novamente salientamos que a íntegra da análise se encontra na dissertação (Dantas, 2019b). As questões propostas no questionário foram necessárias, a nosso juízo, para subsidiar o processo de análise. Avaliamos que tal objetivo foi alcançado.

Em linhas gerais, registramos que os estudantes se mostraram bastante receptivos com toda a atividade. Todos mostraram interesse pela ideia de aliar história e música. Quase todos eles citaram que não haviam trabalhado com canções em sala de aula, analisando suas características distintas e possibilidades, conforme aqui propusemos. Algumas respostas indicaram, inclusive, que alguns sequer trabalharam com canções em aulas de História. Mesmo os que o fizeram evidenciaram ter contato apenas com as letras das canções.

Destacamos, ainda, a opinião dos discentes sobre como a análise da canção nos termos aqui propostos colaborou na compreensão do assunto como um todo. Indo além, a audição das canções, mais do que apenas a leitura da letra, pôde permitir estimular outros sentidos, considerando a relação letra-melodia, bem como a ênfase nas rimas e nos instrumentos musicais utilizados. (Soares, 2017).

Da mesma forma, essa ampliação de horizontes ficou evidenciada quando os questionamos sobre a compreensão do circuito de comunicações (Hermeto, 2012). Todos citaram pelo menos algum mecanismo de mediação, seja de meios de comunicação ou mesmo eventos, ou, ainda, opiniões sobre preconceitos sociais sobre determinados gêneros, a exemplo do brega. 
Retornando à questão do tema mais abrangente, o regime militar, obtivemos relevantes elementos sobre a compreensão deles da canção enquanto documento histórico, ao aludirem sobre o ambiente da canção, o lugar social dos sujeitos da canção e as relações estabelecidas entre eles (Hermeto, 2012). Isso, da mesma forma, colaborou para o estabelecimento de relações com contextos ampliados, considerando, conforme aponta Napolitano (2016), questões de ordem política, ideológica, econômica, social e cultural. Dessa maneira, acreditamos que isso pode favorecer o elemento da criticidade, tão aludido neste trabalho.

Por fim, destacamos que os estudantes avaliaram como um dos pontos fortes a dinâmica de todo o minicurso, além da ideia de trabalharem em grupo. Saliente-se que foi justamente neste quesito que obtivemos como ponto de desafio uma maior integração entre os estudantes. Acreditamos - e a presente experiência nos mostra - que é preciso sempre dar atenção a tal aspecto.

Após a realização do minicurso, a proposta de ensino foi analisada pela banca da sessão de defesa da dissertação (Dantas, 2019b). O trabalho foi aprovado, com a sugestão de inclusão da canção Construção, composta e gravada por Chico Buarque. Lançada em 1971, ela é mais uma canção emblemática do período estudado, bem como possui como tema o trabalho, além de questões técnico-musicais importantes a se considerar.

\section{Considerações Finais}

O presente trabalho teve como objetivo apresentar a construção de uma proposta de ensino que teve a canção popular como objeto de estudo e documento histórico, associando-a ao tema do regime militar, especificamente sobre primeiros momentos da ditadura implantada em 1964 e no período denominado de Anos de Chumbo.

A pesquisa que ensejou esse trabalho indicou que as formas de utilização da canção no ensino de História do IFPB, Campus Cajazeiras, podem não considerar sua totalidade, com análises fragmentadas comumente relacionadas apenas à letra. Baseando-se em pressupostos teórico-metodológicos delineados, concluímos que a canção popular pode e deve ser utilizada no ensino de História.

Fizemos três verificações: a) aliar história e música estimula o interesse dos alunos pelas duas áreas; b) analisar a canção popular em aspectos mais abrangentes, de caráter totalizante, considerando elementos internos e externos da obra, contribui para a compreensão da canção enquanto objeto de estudo; c) utilizar a canção como um documento histórico, à luz de suas características específicas, propicia maior compreensão do tema a ela relacionado.

Conforme pudemos verificar durante todo o processo, acreditamos que os estudantes foram bastante receptivos com a proposta de ensino, estiveram comprometidos com as atividades e, de maneira geral, compreenderam os objetivos do minicurso realizado, além de produzirem conhecimento histórico.

Outrossim, opinamos que a proposta de ensino ora apresentada pode servir de referência em outros contextos escolares, níveis de ensino ou mesmo em espaços não-escolares. Da mesma forma, acreditamos que mais pesquisas podem e devem ser realizadas na esteira do que aqui apontamos, baseando-se, inclusive, no referencial teórico apresentado, considerando as possibilidades e desafios da área de Ensino, ainda mais pela diversidade de possibilidades que a interação entre História e Música pode proporcionar. O mesmo se aplica à temática utilizada na proposta - o regime militar.

\section{Referências}

Aguiar Jr., O. (2005). O planejamento de ensino. Secretaria de Estado de Educação de Minas Gerais.

Araújo, P. C. (2002). Eu não sou cachorro, não: música popular cafona e ditadura militar. Record.

Bauer, M. W. \& Gaskell, G. (2002). Pesquisa qualitativa com texto, imagem e som: um manual prático. Vozes. 
Bloch, M. (1997). Apologia da história. Jorge Zahar.

Brasil. (1996). Lei Federal $n^{o}$ 9.394, de 20 de dezembro de 1996. Estabelece as diretrizes e bases da educação nacional. http://www.planalto.gov.br/ccivil_03/leis/19394.htm

Brasil. (1997). Decreto $n^{\circ} 2.208$, de 17 de abril de 1997. Regulamenta o $\$ 2^{\circ}$ do art. 36 e os arts. 39 a 42 da Lei ${ }^{\circ} 9.394$, de 20 de dezembro de 1996. http://www.planalto.gov.br/ccivil_03/decreto/d2208.htm

Brasil. (2004). Decreto $n^{o} 5.154$, de 23 de julho de 2004. Regulamenta o $§ 2^{\circ}$ do art. 36 e os arts. 39 a 41 da Lei $\mathrm{n}^{\circ} 9.394$, de 20 de dezembro de 1996. http://www.planalto.gov.br/ccivil_03/_ato2004-2006/2004/decreto/d5154.htm

Brasil. (2017). Lei Federal $n^{\circ}$ 13.415, de 16 de fevereiro de 2017. Altera as Leis ${ }^{\circ}$ 9.394, de 20 de dezembro de 1996 , e 11.494 , de 20 de junho 2007, a Consolidação das Leis do Trabalho - CLT, e o Decreto-Lei no 236, de 28 de fevereiro de 1967; revoga a Lei $\mathrm{n}^{\circ} 11.161$, de 5 de agosto de 2005; e institui a Política de Fomento à Implementação de Escolas de Ensino Médio em Tempo Integral. http://www.planalto.gov.br/ccivil_03/_ato20152018/2017/lei/113415.htm

Brasil. (2021). Resolução CNE/CEB $n^{o} 1$, de 15 de janeiro de 2021. Define as Diretrizes Curriculares Nacionais Gerais para a Educação Profissional e Tecnológica. https://www.in.gov.br/web/dou/-/resolucao-cne/cp-n-1-de-5-de-janeiro-de-2021-297767578

Burke, P. (2002). História e teoria social. Edunesp.

Centro Federal de Educação Tecnológica da Paraíba. (2006). Projeto pedagógico do curso técnico integrado em edificações. CEFET-PB.

Ciavatta, M. (2005). A formação integrada: a escola e o trabalho como lugares de memória e de identidade. Trabalho Necessário, 3(3), 1-20. https://doi.org/10.22409/tn.3i3.p6122

Damiani, M. F. (2012) Sobre pesquisas do tipo intervenção - painel de pesquisas do tipo intervenção e sua importância para a produção de teoria educacional. Anais do Encontro Nacional de Didática e Prática de Ensino, 2882-2890.

Damiani, M. F., Et al. (2013). Discutindo pesquisas do tipo intervenção pedagógica. Cadernos de Educação, 45, 57-67. https://periodicos.ufpel.edu.br/ojs2/index.php/caduc/article/view/3822

Dantas, D. N. (2019a). Primavera nos dentes: história e música nos anos de chumbo. Instituto Federal do Rio Grande do Norte. https://educapes.capes.gov.br/handle/capes/568123

Dantas, D. N. (2019b). Primavera nos dentes: uma proposta de ensino de história e música popular. [Dissertação de Mestrado, Instituto Federal de Educação, Ciência e Tecnologia do Rio Grande do Norte]. Plataforma Sucupira. https://sucupira.capes.gov.br/sucupira/public/consultas/coleta/trabalhoConclusa o/viewTrabalhoConclusao.jsf?popup=true\&id_trabalho=9109959

Fico, C. (2015). História do Brasil contemporâneo: da morte de Vargas aos dias atuais. Contexto.

Freire, P. (2010). Pedagogia da autonomia: saberes necessários à prática educativa. Paz e Terra.

Frigotto, G. (2012). Educação omnilateral. In: Caldart et al (org.). Dicionário da educação do campo. Expressão Popular.

Frigotto, G., Ciavatta, M. \& Ramos, M. (2005). A gênese do Decreto n ${ }^{\circ}$ 5.154/2004: um debate no contexto controverso da democracia restrita. In: Frigotto, G., Ciavatta, M. \& Ramos, M. (org.) Ensino médio integrado: concepções e contradições. Cortez.

Gramsci, A. (2001). Cadernos do cárcere: Os intelectuais. Civilização Brasileira.

Gramsci, A. (1982). Os intelectuais e a organização da cultura. Civilização Brasileira.

Hermeto, M. (2012). Canção popular brasileira e ensino de história: palavras, sons e tantos sentidos. Autêntica Editora.

Instituto Federal de Educação, Ciência e Tecnologia da Paraíba - Campus Cajazeiras. (2015). Plano pedagógico de curso - curso técnico em eletromecânica integrado. IFPB.

Instituto Federal de Educação, Ciência e Tecnologia da Paraíba - Campus Cajazeiras. (2013). Plano pedagógico de curso - curso técnico em informática integrado. IFPB.

Instituto Federal de Educação, Ciência e Tecnologia da Paraíba - Campus Cajazeiras. (2014). Plano pedagógico de curso - curso técnico em meio ambiente integrado ao ensino médio na modalidade de educação de jovens e adultos. IFPB.

Le Goff, J. (2013). História e memória. Unicamp.

Leontiev, A. N. Atividade, consciência e personalidade. http://www.dominiopublico.gov.br/pesquisa/DetalheObraForm.do?select_action=\&co_obra=2309

Marx, K. \& Engels, F. (2008). Manifesto do Partido Comunista. Expressão Popular.

Moraes, J. G. V. (2000). História e música: canção popular e conhecimento histórico. Revista Brasileira de História, 20(39), 203-221, 2000. http://www.scielo.br/scielo.php?script=sci_arttext\&pid=S0102-01882000000100009

Napolitano, M. (2017). 1964: história do regime militar brasileiro. Contexto.

Napolitano, M. (2016). História \& música: história cultural da música popular. Autêntica. 
Research, Society and Development, v. 10, n. 16, e344101623818, 2021

(CC BY 4.0) | ISSN 2525-3409 | DOI: http://dx.doi.org/10.33448/rsd-v10i16.23818

Napolitano, M. (2007). História e música popular: um mapa de leituras e questões. Revista de História, 157, 153-171. https://www.revistas.usp.br/revhistoria/article/view/19066

Naves, S. C. (2010). Canção popular no Brasil: a canção crítica. Civilização Brasileira.

Ramos, M. (2008). Concepção de ensino médio integrado. http://www.iiep.org.br/curriculo_integrado.pdf

Ramos, M. (2021). A formação integral no ensino médio (des)integrado no Brasil: a indissociável relação entre trabalho e educação. Trabalho e Educação, 30(1), 117-129. https://periodicos.ufmg.br/index.php/trabedu/article/view/26901

Rocha, H. (2014). A presença do passado na aula de história. In: Magalhães, M., Rocha, H., Ribeiro, J. F. \& Ciambarella, A. (org.) Ensino de história: usos do passado, memória e mídia. FGV.

Rüsen, J. (2001). Razão histórica. UnB.

Saviani, D. (2003). O choque teórico da politecnia. Trabalho, Educação e Saúde, 1(1), 131-152. http://www.scielo.br/scielo.php?pid=S1981$77462003000100010 \&$ script=sci_abstract\&tlng=pt

Saviani, D. (2007). Trabalho e educação: fundamentos ontológicos e históricos. Revista Brasileira de Educação, 12(32), 152-180: http://www.scielo.br/pdf/rbedu/v12n34/a12v1234.pdf

Soares, O. P. (2017). A música nas aulas de história: o debate teórico sobre as metodologias de ensino. Revista História Hoje, 6(11) 78-99 em: https://rhhj.anpuh.org/RHHJ/article/view/325

Tatit, L. (2004). O século da canção. Ateliê Editorial. 